\title{
An Ecopsychological Perspective on Sustainability: The BlindSpot
}

Lori Pye*

\begin{abstract}
As the 2015 deadline for the United Nation's Millennium Development Goals (MDGs) approaches many of the goals and objectives for education, the development agenda and sustainability have not and will not be met.This suggests something is not working - there is a blind spot.The inability to achieve sustainability is based upon much deeper human narratives and behaviors that drive destructive practices: gender exclusion and violence toward women areamong these two core drivers. An ecopsychological education aims to exposeandtransform deeply rooted unconscious narratives that underlie human practices, policies, and decisionsabout how we respond toour world in both creative and destructive ways.
\end{abstract}

Key words: ecopsychology, pedagogy, sustainability, gender, sustainable development, ecology, psychology, narrative

\section{Introduction}

We live in an ecopsychological world. Everything in nature is connected through vast webs of exchanges that are not always obvious or visible. This interconnection includes the web of relationships that create the ethics and values we choose to live by, the perception of self and others, and our worldviews.

We also know there is no waste in nature and that change happens through a decay and renewal processthat includes the decay of human ideologies, attitudes and narratives when they cease to be life serving.Psychologically, sustainability also includes multiple processes that require periodic revisioningas individual and cultural realities change ${ }^{1}$.

As the 2015 deadline for the United Nation's Millennium Development Goals (MDGs) approaches, there is a stark realization that many of the goals and objectives for education, the development agenda, and sustainability have not and will not be met (EFA, 2011; UNDP, 2012). This suggests something is not working. The United Nation's response to this is to reinforce the existing development framework to emphasize "inclusiveness, equality, human rights, sustainability, and unequal development"(UNDP, 2012, p.1).These components have always been a part of the UN agenda. Simply

${ }^{1}$ See Paris, G. (2007), Wisdom of the Psyche: Depth Psychology after Neuroscience 
emphasizing them does not solve the problem as to what is not working. In fact, this furthers an inherent ineffectiveness.

\section{The human issue}

Research across regions and countries has shownthat sustainable development programs and approaches that do not promote gender equality and the full participation of women and girls will not succeed (UNDP, 2012, p.1).Research has also shown linkages between gender inequality, poverty and environmental degradation (EGI, 2013). In the last fifteen years theUN and many of its bodies have promoted and funded many gender equality strategies and programs in support of development and environmental sustainability (UNESCO, 2014). Yet we are no closer to achieving equality than we are to sustainable development. What are we not seeing - what is the blindspot here?

"Sustainable" is more than a development, economic, or environmental issue; it is a psychological issuethat requires an ecopsychological approach. Failure to achieve sustainability is based upon much deeper human narratives and behaviors that drive destructive practices affectinghow we live. What we are not seeing is that "the psychology of the individual is reflected in the psychology of the culture, of nations, and in our world's complex issues" (C.G. Jung, 1953, p.4).An ecopsychological pedagogy is designed to teach how to recognize psychological patterns within systems, and how to mature those relationships.

The majority of post-2015 UN statements regardinggoals and objects for development, social, environmental and economic sustainability now all highlight gender equality (UNESCO 2014). However, thisis where the blindspot resides.To focus on gender equality is a soft way of addressing the real issue. The blind spot we fail to see, recognize, or want to deal with isgender exclusion and violence toward women. This is the core problem and underpins our incapacity to achieve sustainability in any form. Jimmy Carter (2014), former President of the United States, calls the violence toward women and girls, "the most serious and unaddressed worldwide challenge"(p.3). Christine Lagarde, Managing Director of the International Monetary Fund, called gender exclusion aproblem for humanity (2013). Why are we not putting our focus and directing resources toward this issue?To achieve gender equality, gender exclusion must first be eradicated and violence toward girls and women in all forms ended.

Gender exclusion and violence toward women are based on hierarchic modes of thinking,whichare not new. These issues are being acknowledged by economists, political scientists, researchers, historians, environmental scientists, and forward thinking global leaders, precisely because theyfoster economic, environmentaland social instability and are an affront to all humanity. These behaviors arebased upondysfunctional and injurious narratives that constellate hierarchism and reductionism, preventing diversity and cultural evolution.It is impossible forthe United Nations and its bodies to ensure that "globalization becomes a positive force for all the world's peoples,"(UNDP, 2012, p.1) when half of the world'spopulation is not included due to discriminating laws, archaic social practices and the cultural acceptance of such.

Gender exclusion, ecological destruction and continued "microaggressiontoward women” (Hudson, Ballif-Spanvill, Caprioli, and Emmett, 2014, p. 17) are inconsistant 
with life.They take many forms, including soul violence of all sorts, lack of access to education, health care and economic markets; exclusion from participation in societal decision making councils; and lack of equity in family law (Hudson et al, 2014).Indeed, there is a continued exclusion of womenfrom participation in environmental issues and concerns in which women are deeplyinvested (Environment and Gender Index, 2013). How these denigrating practices translate into the global culture is striking:

- Women make up half of the world's population, yet represent a staggering $70 \%$ of the world's poorliving on less than $\$ 1$ a day (International Labor Organization, 2003);

- Women do two-thirds of the world's work, produce half of the world's food, but earn only $10 \%$ of the world's income, and own less than one percent of the world's property $^{2}$;

- 100 to 140 million girls and women around the world have undergone genital mutilation, including 6.5 million in Western countries. The majority of countries rarely engage in this practice. However, countries where more than half of the women have their genitals cut include Saudi Arabia, Indonesia and Egypt (WomenStats Project, 2011a)

- In developing countrieswhereforced adolescent marriagesis commona girl or a woman dies every minute in giving birth.Marriage under the age of 18 has been correlated with higher rates of dying young, health problems, living in poverty and illiteracy. Countries in which underage marriage is common and encouraged include India, Turkey, and Panama, among many others (WomenStats Project, 2011b);

- The countries that have more than 300 maternal deaths per 100,000 live births include almost all of central Africa, Pakistan and Bolivia(WomenStats Project, 2010a);

- The countries in which women lack physical security (physical security defined as- "fewer laws against domestic violence, rape, and marital rape, their enforcement, the taboos or norms about reporting the crimes and existence of 'honor killings') include Cambodia, Morocco and Peru, among many others in Africa and the Middle East(WomenStats Project, 2009, 2011c);

- Violence and trafficking of girls and women is still legal in many countries and practiced widely around the world. The countries in which trafficking is not illegal and commonly practiced include Myanmar, Venezuela and North Korea. Studies have found

${ }^{2}$ This data is drawn from organizations that collect and aggregate information at a global level, including the U.N. Millennium Campaign, the World Bank, UNESCO, and Population Fund. Secondary information retrieved 23June 2014 from http://www.womensfundingnetwork.org 
that 70 per cent of trafficked women end up in the sex trade(WomenStats Project, 2011d);

- Countries in which 0 to only 10 per cent of parliament is composed of women include China, Japan and Brazil. Research has found that achieving a critical mass of onethird of women in government can help societies move beyond gender-centric issues. (WomenStats Project, 2010b)

Some of the most sobering statistics show that there is no country or nation where women are physically secure (WomenStats Project, 2011e). Research has also shown "the best predictor of a state's peacefulness is its level of violence against women. Even among democracies, those with poor physical security for women are less peaceful than democracies with good physical security for women (Hudson et al, 2012, p. 205; Carter, 2014).

In 1997, UNIFEM estimated that the monetary value ofthe unpaid labor of women translated into around $40 \%$ of the world's gross product (WGP) (Hudson et al, 2014, p.14).It is hard to believe that half the population has been left out of the officialcalculation of GNP. In her opening speech at the World Economic Forum,Christine Lagardeemphasized stronger inclusion, and a shared economic prosperity when she stated:

"All studies point to the economic benefits of full female participation in the labor force, in the economy, in society. One recent study estimates that by simply raising women's employment rates to the level of men, GDP would jump significantly - by 5 percent in the United States, 9 percent in Japan, 10 percent in South Africa, 27 percent in India, and 34 percent in Egypt." (2013)

This is not a promotion of unsustainable growth, but rather it is a promotion of equity in economic value. It is now widely acknowledgedthat the exclusion of women's labor, violence toward women, and barring womenfrom participationin decision making processes are detrimental to the economic, environmental and social systems. Yet, laws and policies are still in place around the world that hold these practices in place.

The questions seem obvious: Why are we not insisting on an end to violence toward women and girls around the world? Why continue to fund countries, nations, policies, and strategies that not only exclude women, but consciously or unconsciously perpetuate violence toward them? How might these practices be finding cover under a sustainable development umbrella?

\section{Conclusions}

If there are no ethical considerations within sustainable development, then deeper problems are easily camouflaged with "engaging rhetoric or superficial agreements" (Rolston, 2012, p. 37). Development that reduces equality, exchange and distribution of resources, plurality, economic fairness, biodiversity, and enables violence toward women is what Vedana Shiva calls "maldevelopment" (1989, p.5). 
Maldevelopment inhibits economic, environmental, social and cultural flourishing.Sustainable development can no longer not invest in girls and women.

We cannot achieve equality or sustainability in our culture or nations unless we develop it in our psychologies. We create our reality, order our world, imagine our cosmology and develop our narratives based upon the structures dominant in our cultures. An ecopsychological approach is essential to the task of initiatingchanges in our individual as well as in our cultural stories. The human psyche is cultural and cultures evolve like all ecosystems. Ecopsychology offers ways to track change and set priorities; it can offer new narratives for a sustainable future.

The Convention on the Elimination of all Forms of Discrimination against Women (CEDAW) is known as "the bill of rights for women's equality" (Carter, 2014, p. 180). It defines what constitutes discrimination against women and sets up an agenda for national action to end such discrimination. By accepting the Convention, states commit themselves to undertake a series of measures to end discrimination against women in all forms (UN Womenwatch, 2014).However, it has been observed that "unless a right is said to expressly belong to women, it may not in fact be assumed to do so" (Hudson et al, 2012, p.123). CEDAW was adopted in 1979 by the UN General Assembly to address this problem.

However, research has exposed lack of truthfulness and accuracy in reporting compliance. Although nations sign the Convention, there is too oftenlittle intention or action toward honoring it. (Hudson et al, 2012, p.124; Carter 2014). CEDAW has been ratified by all nations except Iran, Palau, Somalia, Sudan, and Tonga. Embarrassingly, the United States, signed the treaty in 1980, but has not ratified it. This is due to the opposition of conservative groups and the religious right who promote the same attitudes of ignorance and inequality that we see in countries openly allowing violence toward women and gender exclusion.

Biologist E. O. Wilson has commented that we are not the most numerous species on the planet, but we are the most destructive. "The human condition is an endemic turmoil rooted in the evolution process that created us. The worst in our nature coexists with the best..." (2012, p. 56). The narratives that hold in place destructive behaviors and practices toward the environment and toward women are dangerously unconscious. They represent ecopsychological issues that profoundly affect our world.

Achieving sustainability across social, economic and environmental sectorsmust be led by educational efforts. Where education leads, development will follow. Ecopsychology is essential to creating a new framework for sustainable developmentthat servesthe complexities of both an ecological and a psychological world.

\section{References}

Carter, Jimmy. (2014). A call to action: Women, religion, violence, and power. New York:

Simon \& Schuster.

Education for All (EFA). (2011). Global Monitoring Report-Teaching and learning: Acbieving quality for all. Paris: UNESCO.

Environment and Gender Index (EGI). (2013).Pilot report. Washington, DC: IUCN

Hudson, V., Ballif-Spanvill, B., Caprioli, M., \& Emmett, C.F. (2012). Sex and world peace. New York: Columbia University Press. 
International Labor Organization.(2003). Facts on women at work. Geneva, Switzerland.

Retrieved from http://www.ilo.org/wcmsp5/groups/public/---dgreports/

dcomm/documents/publication/wcms_067595.pdf.

Jung, C.G. (1953). Two essays on analytical psychology, CW, Vol. 7 (Gerhard

Adler (Translator), R. F.C. Hull (Translator). New York: Bollingen Foundation, Inc. Lagarde, Christine. (2013). World Economic Forum Address. Davos, Switzerland.

Paris, G. (2007). Wisdom of the psyche: Depth psychology after neuroscience. New York:

Routledge.

Rolston, Holmes, III. (2012). A new environmental ethics: the next millennium for life on earth.

New York: Routledge.

Shiva, Vendana (1989). Staying alive: Women, ecology and development. New Delhi, India.

United Nations Development Program (UNDP). (2012). Powerful synergies: Gender equality, economic development and environmental sustainability. New York:UNDP.

United Nations Education, Scientific and Cultural Organization (UNESCO). (2014). Priority gender equality action plan 2014-2021.Paris: UNESCO.

Wilson, E.O. (2012). Social conquest of the earth. New York: W.W. Norton/Liveright Pub.

WomenStats Project. [Map]. (2009). Women's physical security. Retrieved from

http://womanstats.org/newmapspage.html.

WomenStats Project. [Map]. (2010a). Maternal mortality rate. Retrieved from

http://womanstats.org/newmapspage.html.

WomenStats Project. [Map]. (2010b). Government participation by women.Retrieved from http://womanstats.org/newmapspage.html.

WomenStats Project. [Map]. (2011a).Prevalence of female genital cutting. Retrieved from http://womanstats.org/newmapspage.html.

WomenStats Project. [Map]. (2011b).Practice of child marriage for girls and Laws concerning child marriage for girls. Retrieved from http://womanstats.org/newmapspage.html.

WomenStats Project. [Map]. (2011c). Prevalence of rape, Inclusivity of

laws concerning rape, and Rate of murder of women. Retrieved from

http://womanstats.org/newmapspage.html

WomenStats Project. [Map]. (2011d).Trafficking of women, Retrieved from

http://womanstats.org/newmapspage.html

WomenStats Project. [Map]. (2011e).Combined scale of the prevalence and sanction of rape and sexual assault of women. Retrieved from http://womanstats.org/newmapspage.html 